\title{
MODERNIZAÇÃO E MODERNIDADE EM MARINGÁ 1947-1967: \\ EPISÓDIOS DE ARQUITETURA E CIDADE \\ EM UMA FRENTE PIONEIRA
}

\section{MODERNIZATION AND MODERNITY IN MARINGÁ 1947-1967:}

\author{
EPISODES OF ARCHITECTURE AND A CITY ON A PIONEERING FRONT
}

\author{
Ana Carolina Pussi de Brito a, B, C, D, E, F \\ André Augusto de Almeida Alves A, B, C, D, e, F \\ Universidade Estadual de Maringá, Departamento de Arquitetura e Urbanismo, Programa Associado \\ de Pós-Graduação em Arquitetura e Urbanismo, Maringá, Paraná, Brasil
}

\begin{abstract}
R E S U M O : O artigo se debruça sobre a arquitetura, a urbanização e o urbanismo da área colonizada pela CTNP/CMNP no norte do Paraná, a partir de reflexôes sobre as dinâmicas de circulação de ideias. Nele, é retomado o debate acerca dos processos de intercâmbio cultural instaurado por Schwarz e Carvalho Franco - as "ideias fora do lugar" - no âmbito da crítica às teses dualistas do subdesenvolvimento brasileiro. Partindo de uma abordagem que busca aproximar arquitetura, cidade e processo social, efetua-se, inicialmente, uma revisão crítica da historiografia sobre o empreendimento colonizador, a rede de transportes, a urbanização do território, o traçado das cidades e sobre alguns de seus edifícios. Por conseguinte, realiza-se uma leitura do plano urbanístico de Jorge de Macedo Vieira para a cidade de Maringá e dos projetos de José Augusto Bellucci para a CMNP, para o poder público $e$ para a Igreja Católica. Assinale-se que a investigação dessas dinâmicas pode contribuir para a constituição de novas perspectivas no campo das investigações sobre processos de urbanização e construção do território e das cidades brasileiras.
\end{abstract}

P A L A V R A S - C H A V E : circulação de ideias; Maringá, PR; modernização; Jorge de Macedo Vieira; José Augusto Bellucci.

A B S T R A C T : This article focuses on the architecture, urbanization and urbanism of an area colonized by the CTNP/CMNP in northern Paraná, from reflections on the dynamics of the circulation of ideas. It resumes the debate regarding the processes of cultural exchange as introduced by Schwarz and Carvalho Francothe "misplaced ideas" - in the context of criticism aimed at the dualistic theories of Brazilian underdevelopment. Based on an approach that brings together architecture, city and social process, it initially performs a critical historiographical review that covers the constitution of the colonizing enterprises, the transport network, urbanization of the territory, the layout of the city and some of its buildings. It essays a renewed interpretation of the urban plan by Jorge Macedo Vieira for the city of Maringá and the architectural designs by José Augusto Bellucci for the CMNP, the local authorities and the Catholic Church, which are the object of its attention. It is assumed that an analysis of these dynamics may cast new perspectives on the investigation of the urbanization processes and the construction of Brazilian territory and cities.

K E Y W O R D S : circulation of ideas; Maringá, PR; modernization; Jorge de Macedo Vieira; José Augusto Belluci.

DOI: http://dx.doi.org/10.22296/2317-1529.2016v18n1p129

Contribuição de cada autor/a: A. fundamentação teórico-conceitual e problematização; B. pesquisa de dados e análise estatística; C. elaboração de figuras e tabelas; D. fotos; E. elaboração e redação do texto; F. seleção das referências bibliográficas. 


\section{INTRODUÇÃO}

O processo de ocupação, urbanização e constituição das expressóes arquitetônicas e urbanísticas da área colonizada pela Companhia de Terras Norte do Paranál Companhia Melhoramentos Norte do Paraná (CTNP/CMNP) é marcado por relaçóes estabelecidas entre uma frente pioneira e uma série de lugares próximos e longínquos, concretos e abstratos, institucionais e de mercado, do capital e do trabalho, da economia e da política, do pensamento e do imaginário. Construindo-se nessas relaçôes e, ao mesmo tempo, participando da construção delas, a arquitetura, o urbanismo e a urbanização - e sua historiografia - são, igual e simultaneamente, seu produto e lugar.

O alhures revela-se como uma porta de entrada frequente ao universo dessas relaçóes. Muller (1956, p. 89), por exemplo, define a experiência da CTNP como "um capítulo da vida paulista, mas em território paranaense". Há também a discussão sobre a presença dos preceitos da garden city britânica no urbanismo de Jorge Macedo de Vieira, especificamente no plano que ele elaborou para a cidade de Maringá (ANDRADE, 2000; BONFATO, 2003; ANDRADE; CORDOVIL, 2008; ROSANELI, 2009; REGO, 2009; CORDOVIL, 2010). Por sua vez, nos discursos de autores locais sobre os primeiros edifícios projetados por José Augusto Bellucci para Maringá, observa-se a reprodução de interpretaçôes que aliam arquitetura moderna, valores e materiais locais direcionados à construção de uma identidade nacional. E, para finalizar, é possível verificar discursos que associam as amplas estruturas de concreto aparente projetadas por Bellucci a um "brutalismo paulista" (VERRI JÚNIOR, 2001; REGO, 2012).

O teor dos processos e operaçóes de circulação de ideias assume, aqui, especial relevo. De fato, abordagens marcadas por noçôes de influência, realizaçôes parciais, cópias, simplificaçôes e adaptaçôes técnicas, programáticas, tipológicas, plásticas e formais, frequentes na produção historiográfica sobre a arquitetura e urbanismo de frentes pioneiras, deixam transparecer dissonâncias frente aos instrumentais teóricos gerados no âmbito da história intelectual em que as dinâmicas de circulação de ideias ocupam posição central.

Considerando a importância da questão da circulação de ideias na América Latina, esse debate é apresentado, de forma crítica, já na primeira parte deste artigo. Parte-se do pressuposto de que a polêmica existente no pensamento social brasileiro e latino-americano em torno da discussão sobre as "ideias fora do lugar" é promissora para a investigação do objeto ora considerado, isto é, o processo de colonização e modernização assumido pela CTNP/CMNP em Maringá. Não resta dúvida de que esse amplo universo de reflexôes sobre a concepção, produção, apropriação, reelaboraçáo e ressignificação de ideias e ideais de modernização e modernidade marca a construção da paisagem urbana de significativas porçôes do território brasileiro ocupadas a partir de meados do século XX.

\section{LUGAR DAS IDEIAS, IDEIAS DO LUGAR E A HISTÓRIA DAS IDEIAS LATINO-AMERICANAS}

O ensaio As ideias fora do lugar (1973), de Roberto Schwarz, tornou-se um marco da reflexão da história intelectual e das ideias latino-americanas ao aproximar-se do campo da produção cultural tomando, como ponto de partida, a discussão acerca 
da coexistência de ideias liberais e de sociedades atrasadas, a qual marca a historiografia dos processos de independência dos países latino-americanos desde o século XIX ${ }^{1}$.

Iniciando seu ensaio com citaçôes de opositores e defensores da escravidáo, Schwarz aponta para um quadro em que certa percepção ou sensaçáo de "impropriedade de nosso pensamento [...] foi de fato uma presença assídua, atravessando e desequilibrando, até no detalhe, a vida ideológica do Segundo Reinado" (SCHWARZ, 2000, p. 13). Esse quadro é evidenciado, segundo o autor, pela prosa literária do período e pela posterior produção historiográfica. A afirmação de Schwarz (2000, p. 29) de que, "ao longo de sua reprodução social, o Brasil incansavelmente póe e repóe ideias europeias, sempre em sentido impróprio», recorrentemente pinçada de seu contexto inicial, incendiou o debate posterior sobre o tema e condensou uma ampla e longa polêmica que repercute ainda nos dias atuais. Nesse sentido, o autor chega a afirmar que "[é] nesta qualidade [de 'ideias fora do lugar'] que elas serão matéria e problema para a literatura" (SCHWARZ, 2000, p. 29), e, poderíamos acrescentar, para a historiografia, arquitetura e para o urbanismo ${ }^{2}$.

Após abordar as temáticas da escravidão e do favor, introduzindo um viés deslizante e ambíguo nas ideias liberais - "reconhecivelmente nossas, nessa mesma qualidade" -, Schwarz novamente assinala os desdobramentos dessas mesmas ideias no campo do pensamento brasileiro, bem como a dinâmica de apropriação e de reelaboração delas:

Assim, posto de parte o raciocínio sobre as causas, resta na experiência aquele "desconcerto" que foi nosso ponto de partida: a sensação que o Brasil dá de dualismo e factício - contrastes rebarbativos, desproporçóes, disparates, anacronismos, contradiçóes e o que for - combinaçóes que o Modernismo, o Tropicalismo e a Economia Política nos ensinaram a considerar (SCHWARZ, 2000, p. 21).

Os "desconcertos", que, segundo Schwarz, compóem um panorama da "comédia ideológica" brasileira "diferente da europeia" (SCHWARZ, 2000, p. 12, grifo do autor), são por ele extensamente exemplificados, abordando inclusive o caso da arquitetura residencial paulista no século XIX:

A transformação arquitetônica era superficial. Sobre as paredes de terra, erguidas por escravos, pregavam-se papéis decorativos europeus ou aplicavam-se pinturas, de forma a criar a ilusão de um ambiente novo, como os interiores das residências dos países em industrialização. Em certos exemplos, o fingimento atingia o absurdo: pintavam-se motivos arquitetônicos greco-romanos - pilastras, arquitraves, colunatas, frisas, etc. - com perfeição de perspectiva e sombreamento, sugerindo uma ambientação neoclássica jamais realizável com as técnicas e materiais disponíveis no local. Em outros, pintavam-se janelas nas paredes, com vistas sobre ambientes do Rio de Janeiro, ou da Europa, sugerindo um exterior longínquo, certamente diverso do real, das senzalas, escravos e terreiros de serviço (REIS FILHO, p. 14-15 (manuscrito) apud SCHWARZ, 2000, p. 22-23).

O trecho ilustra, com clareza, a tendência, então vigente na produção historiográfica, de situar as análises da produção local em termos de contradições entre a realidade nacional e as ideias estrangeiras, na contramão da superação, nas palavras de Schwarz (2000, p. 25), do "desacordo entre a representação e o que, pensando bem, sabemos ser o seu contexto". Realmente, como assinala o autor, diante
1 Segundo Schwarz e BoteIho (2008, p. 147), "há trinta anos, em 1977, era publicada a primeira edição de $A o$ vencedor as batatas", iniciado pelo "ensaio teórico-metodológico, hoje célebre, 'As ideias fora do lugar' - ensaio que tem sido muito debatido, e mal compreendido, talvez por conta de seu título provocador".

2 Este fato é perceptível, por exemplo, quando Rocha-Peixoto (2014, s.p.) comenta a introdução da "antinomia 'centro-periferia' no debate contemporâneo sobre 'regionalismo"": "trata-se de driblar os dois hábitos atávicos entre os quais oscila a auto-imagem latino-americana: de um lado a atitude rasteira que parte de uma vanglória subdesenvolvida, nega a Europa e América do Norte e acha que pode tratar do quintal de casa como se aquilo fosse o Centro do Mundo. $\mathrm{Na}$ extremidade oposta há os bovaristas passivos e colonizados. Com insuperável complexo de inferioridade declaram a impotência da periferia". 
3 Em entrevista, Schwarz responde a Schwarcz e BoteIho $(2008$, p. 152) da seguinte maneira: "a seu modo, o título é uma piada. Procura nomear e sublinhar uma impressão, mas não para dizer que ela está certa. Que as ideias modernas estejam fora do lugar no Brasil é o maior lugar comum do pensamento conservador brasileiro, e eu não ia repeti-lo".

4 Nesse sentido, enquanto para Schwarz o favor passa a ser a mediação quase universal numa sociedade cuja relação produtiva de base é assegurada pela força, para a autora, o favor "foi tecido como desdobramento da produção lucrativa", e, dentro dessa visão globalizante, cumpriu o papel que o princípio da "igualdade" havia desempenhado na Europa (CARVALHO FRANCO, 1976, p. 62). de tais "desajustes" - entre os quais se destaca o da prática das ideias liberais no Brasil - "pouco ajuda insistir na sua clara falsidade"; em vez disso, "[m]ais interessante é acompanhar-lhes o movimento, de que ela, a falsidade, é parte verdadeira” (SCHWARZ, 2000, p. 26). Partindo da dialética da produção cultural, em lugar de reproduzir o dualismo centro-periferia ${ }^{3}$, Schwarz efetua sua crítica e examina, com precisão, as complexas dinâmicas que marcam os processos de circulação de ideias e de intercâmbio cultural estabelecidos no âmbito do capitalismo.

O conteúdo do ensaio gerou grande polêmica, mobilizando um forte debate na década de 1970. Ele foi refutado por Maria Sylvia de Carvalho Franco na entrevista As ideias estão no lugar (1976). A autora faz uma crítica às leituras dualistas, "desde a maneira como foram formuladas pelo romantismo nacionalista até o realismo da atual teoria da dependência" (CARVALHO FRANCO, 1976, p. 61). Carvalho Franco reconhece na então "nova teoria das ideias fora do lugar" uma "variante das interpretaçôes que combinam diferentes modos de produção" (p. 61-2, grifo da autora), vendo nela a persistência do entendimento do centro e da periferia como partes heterogêneas, embora articuladas, de um todo que as transcende - limitação que adviria da filiação ao quadro do pensamento brasileiro antes exposto. A controvérsia em relação ao entendimento do binômio centro-periferia como espécies de situações ou desenvolvimentos particulares dentro do movimento imanente da constituição e reprodução do sistema capitalista mundial fica patente quando a autora assinala a inadequação até mesmo da "dissociação analítica de suas partes"4.

Palti (2002, p. 3) recoloca, muito posteriormente, esse debate em termos da percepçáo de Schwarz do "potencial contido nos postulados dependentistas, que até então haviam apenas se aplicado no campo da história econômica e social, para o âmbito da crítica literária e cultural". Consideradas as nuances do debate até aqui exposto, tal formulaçáo parece excessivamente crua. Por outro lado, a agudeza do olhar desse autor para a complexidade das questóes em jogo revela que seu exercício é útil para a construção do argumento do texto dele. Segundo ele, a polêmica levantada por Carvalho Franco instaura um problema metodológico mais geral, pois as ideias, para ela, jamais estão "fora do lugar", dado que sempre servem a algum propósito. A autora, em função da consistência de sua posição, diluiria a problemática relativa à natureza periférica da cultura local, destacando o caráter eminentemente político das atribuições da "alteridade" das ideias (PALTI, 2002, p. 11). Porém, como Palti salienta (2002, p. 9), Schwarz focaliza não a incompatibilidade entre as ideias e a sociedade brasileira, mas sim o desajuste dessa sociedade em relaçáo a si mesma - ou seja, as suas contradiçóes -, residindo aí - e não numa base relativa - o conteúdo político referido. Ainda que para Carvalho Franco esse tratamento signifique contrabandear com novo nome a oposição tradicional entre duas lógicas de desenvolvimento - a propriamente capitalista e a capitalista-periférica -, não passa igualmente despercebido a Schwarz o fato de que não se trata de duas lógicas, mas sim de uma, a saber, a busca do lucro, marcada por conflitos e contradiçóes, tanto no centro quanto na periferia. Tal percepçáo faz com que Palti conclua que a postura de Schwarz é mais sensível às particularidades das manifestaçôes culturais locais.

Encontram-se em jogo, para Schwarz, as implicaçôes desse debate para a viabilidade de um projeto emancipatório na região; ou seja, antes de suscitar a crítica em torno de uma recaída no tipo de dualismo que tentava precisamente combater, ao "perder de vista os processos reais de produção ideológica no Brasil" (CARVALHO 
FRANCO, 1976, p. 62), trata-se de afirmar a necessidade de, ao se debruçar sobre a produçáo cultural e intelectual local, reelaborar ou reconstruir universos de ideias e sistemas de pensamento 5 . Daí a profundidade e sutileza da contribuição de Schwarz à crítica literária e às ciências sociais brasileiras (ARANTES, 1992). Nas palavras de Schwarcz e Botelho (2008), "mais do que entender 'traduçóes' era preciso pensar em 'deslocamentos' e na viagem das ideias - no quiproquó das ideias como diz Schwarz", de modo a inscrevê-las no movimento geral da sociedade. Agindo assim, é possível evitar, por exemplo, o perigo da repetição do dilema antropofágico: "[...] en este sentido, las propias ideas libertarias son con frecuencia una Idea fuera de lugar, y sólo dejan de serlo cuando se las reconstruye a partir de las contradicciones locales" (SCHWARZ apud PALTI, 2002, p. 10).

Para entender o universo conceitual do trabalho de Schwarz, o ponto de referência fundamental é a obra de Antônio Candido, que, com mérito, desenvolveu um modelo de aproximação sociológica da literatura, sem obliterar sua dimensão estética. $\mathrm{O}$ método crítico de Schwarz é elaborado e desenvolvido a partir desse modelo, tratando de combinar análise estética com análise histórico-social. Ele procura superar, dessa maneira, tanto os enfoques de "conteúdo", que anulam a riqueza da obra literária, quanto as aproximações formalistas, que afastam as produções artísticas do contexto e das condições materiais de sua produção. A chave seria o conceito de forma aplicado, simultaneamente, na percepção do contexto social em que nasce uma obra e na identificação dos procedimentos de construção linguístico-literária. Schwarz destaca a capacidade de visão "estereoscópica" presente em Candido, efetuando uma analogia com o procedimento de Benjamin nos estudos sobre Baudelaire: "nestes são privilegiadas as correspondências sociais entre a lírica e as figuras do submundo urbano ou os dramas de funcionamento do mercado", entendidas, "em linguagem benjaminiana, dentro de uma constelaçáo” (ALAMBERT, 1998, p. 238).

A contribuição de Schwarz advém de seu aporte teórico, que põe em relação dialética forma e conteúdo, estrutura e história, análise literária e reflexão social e, especificamente, centro e periferia. O desafio do autor, segundo Palti, reside no modo de explicar a universalidade da obra de Machado de Assis, sem renunciar os vínculos com uma condição periférica. Em seu exercício reflexivo, Palti aponta como óbice para esse intento o fato de a autoparodizaçáo do gênero náo constituir uma peculiaridade brasileira ou latino-americana, algo semelhante ao que ocorre com os elementos derivados da noção de entrelugares - desvio da norma -, de Santiago (1970) ${ }^{6}$.

$\mathrm{O}$ autor analisa as implicações dessas reflexões para a historiografia das ideias latino-americanas, sobretudo a questão dos modelos putativos. Por um lado, a invocação de tais modelos pressupóe a concepção de que as ideias têm "seu lugar apropriado", o que limita a história das ideias latino-americanas ao seu rebatimento sobre o contexto local ${ }^{7}$. Além disso, tal invocação exige a simplificação e o obscurecimento dos conteúdos problemáticos da história das ideias europeias, o que bloqueia, por sua vez, a percepção de que idiossincrasias ou peculiaridades latino-americanas não são passíveis de descrição como categorias não europeias - aspecto em relação ao qual Schwarz tinha particular lucidez. Por outro lado, uma visão reducionista das arestas problemáticas locais - por exemplo, sua irrefletida qualificação como "desconcerto" ou "ideia fora do lugar" - tende a impedir que esses modelos sejam interrogados criticamente, obstruindo, antecipadamente, qualquer eventual problematização - problematização que "[...] é precisamente, como assinala Schwarz, o aspecto
5 Revela-se a importância da "dissociação analítica de suas partes" na análise da luta de classes, ou seja, como dado metodológico, em vez de mero facilitador.

6 Palti encontra os nós mais importantes dos esquemas interpretativos de Schwarz, realocando sua significativa contribuição para o plano de análise da história da linguagem e seus modos de articulação e postulando um modelo que envolve a dimensão pragmática da linguagem.

7 Ponto em que considera sintomático o fato de que suas abordagens tradicionais fracassem na missão autoimposta de encontrar suas peculiaridades 
8 Tais postulados remetem, em maior medida, ao dualismo da teoria do subdesenvolvimento, que supera as interpretações do subdesenvolvimento como uma fase correspondente à infância dos países capitalistas centrais, em favor de sua definição como produto histórico do desenvolvimento destes últimos, resultante de fatores como o predomínio do setor agrário-exportador unido a interesses estrangeiros e à assimetria nas relações de troca, passível de superação pela ação do Estado na articulação de classes sociais e na indução da industrialização em prol do desenvolvimento. mais interessante na obra de Machado de Assis: como ele se manifestou dentro dos problemas que eram inerentes a ele" (PALTI, 2002, p. 25). Palti vai de encontro às abordagens em que os "modelos" constituiriam construções a priori e as "culturas locais" constituiriam, inevitavelmente, "destinos", os quais seriam eternos produtores de "cópias". Essas formulaçôes encontram desdobramentos na própria produção de Schwarz. Em Nacional por subtração (1987), por exemplo, ele afirma que "a historiografia da cultura ficou devendo o passo globalizante dado pela economia e sociologia de esquerda, que estudam o nosso 'atraso' como parte da história contemporânea do capital e de seus avanços” (SCHWARZ, 1987, p. 33).

Deve-se notar que tal passo consiste no oposto à filiaçáo a uma teoria da dependência, cuja "lógica materialista e macroestruturalista", na visão de Almandoz (2002, p. 2, 6), acabaria por superestimar a importância da dependência econômica e reduziria "as mudanças sociais à imposição de modelos culturais do exterior". Recusando as "premissas marxistas" da Escola da Dependência, Almandoz (2002, p. 22-23) se distancia do entendimento da teoria da dependência como aprofundamento das complexas dinâmicas internas e das estruturas de dominação que compreendem forças sociais e políticas, internas e externas, em sua integração com o capitalismo (MANTEGA, 1997, p. 28), bem como de toda uma geração de pensadores cujos trabalhos "multiplicaram-se e caminharam em várias direçôes", como a Crítica à razão dualista, de Francisco de Oliveira, e $O$ capitalismo tardio, de João Manuel Cardoso de Mello. Ao invés de uma monolítica e esquemática teoria da dependência, tem-se, segundo Mantega (1997, p. 28), uma Nova Esquerda, que supera paulatinamente a dualidade centro-periferia.

Tal produção intelectual possui implicaçôes na "importação de ideias de planejamento e projeto urbano", proposta por Almandoz (2002, p. 2, 4) como substituta da exportação (imposiçáa) de modelos, no contexto da globalização. Esse autor retoma algumas assertivas relativas a estruturas estabelecidas por elites que representam interesses estrangeiros, ao rebatimento de economias voltadas à exportação na rede de cidades e à perpetuação de termos desfavoráveis de intercâmbio (ALMANDOZ, 2002, p. 22-23), que na verdade contrariam até mesmo a possibilidade de um desenvolvimento capitalista dependente e associado na América Latina, como proposto pela teoria da dependência. Tais implicaçôes alcançam sua contraface na preocupação com "os modos distintos com que estes [modelos] foram incorporados nas capitais das repúblicas emergentes” (ALMANDOZ, 2002, p. 2, grifo nosso). Uma mesma ordem de questôes é posta às "influências que chegam da Europa" (ALMANDOZ, 2002, p. 2-3, grifo nosso), às imagens de Romero e Rama da cidade burguesa como "imitação quase total da Europa", satisfazendo necessidades de expansão e o "genuíno desejo e fantasia urbana" de elites locais (ALMANDOZ, 2002, p. 4, grifo nosso) ${ }^{8}$.

Se, de fato, as "noções de 'transferência', 'exportação' e 'importação' não implicam uma imposição cultural” (ALMANDOZ, 2002, p. 6), é também verdade que há um quadro complexo que exige a exploração não apenas da "importação urbana" e da importação "resultante das necessidades culturais das elites dependentes"; um quadro que apresenta uma demanda maior que a de "enriquecer a imposição unilateral e determinística de conceitos colonialistas pela incorporação de elementos locais", por meio de noçôes como as de "recriação", compreendida como "empréstimo seletivo", ou "reinvenção cultural", no sentido de "inovação sintética" (ALMANDOZ, 2002, p. 6). Encontram-se aqui questôes como a dos modelos putativos e dos sentidos dos fluxos de circulação de ideias. 
Esse debate é também abordado por Canclini (1998, p. 75), que vê As ideias fora do lugar como um texto que inaugura a ruptura com a "ideologia do reflexo e de qualquer suposiçáo sobre correspondências mecânicas entre base material e representaçóes simbólicas" - uma ruptura necessária para a superação de noçôes de "transplante" ou "enxerto" e, ao mesmo tempo, favorável a "uma visão mais complexa sobre a modernidade latino-americana” (CANCLINI, 1998, p. 70). Essa visão supóe o questionamento de "imagens otimizadas" - modelos do centro - e a superação de determinismos socioeconômicos (CANCLINI, 1998, p. 71-72), a fim de chegar a um "modo de experiência intelectual" que assuma os "conflitos internos, [a] dependência exterior e [as] utopias transformadoras" - os "projetos"9 (CANCLINI, 1998, p. 76-78).

Com base nessas reflexôes sobre o pensamento social brasileiro e latino-americano, este artigo realiza uma análise do processo de ocupação e construção da paisagem urbana do empreendimento colonizador da CTNP/CMNP na regiáo noroeste do Paraná, por meio de episódios específicos do urbanismo e da arquitetura maringaense entre 1947 e 1967. Pretende-se, a partir do marco teórico apresentado, discutir tal produção arquitetônica e urbanística e sua respectiva historiografia aqui considerada como parte do construto ora examinado -, visando a identificar o conteúdo e o sentido de modernização e modernidade nelas presentes. $\mathrm{O}$ texto concentra-se na revisão da construção dos cenários econômicos, das condicionantes do processo de ocupação territorial, dos dados que marcam a constituição da paisagem urbana (indo desde as vias de comunicação até o traçado das cidades), da trajetória de arquitetos e do processo de concepção e materialização de edifícios. Esse conjunto de elementos oferece à investigação a possibilidade de entrever a relação entre arquitetura e sociedade.

\section{UM EPISÓDIO URBANÍSTICO: TERRITÓRIO E URBE MODERNOS NO NORTE DO PARANÁ, A CIDADE DE MARINGÁ}

A inserção da zona de colonização recente do norte do Paraná nos quadros de modernização do país no pós-Segunda Guerra Mundial é feita, recorrentemente, pela associação do interior do Paraná com o estado de São Paulo - associação advinda do extravasamento da cultura cafeeira paulista e da consequente organizaçáo da rede de cidades da regiáo assentada em uma produção mercantil e dinâmica, com grande adensamento populacional. A esse cenário, devem ser acrescentadas a criação de núcleos urbanos subsidiados pela atividade agrícola cafeeira (DE ANGELIS et al., 2007) e pela atuação de empresários paulistas no comando de companhias colonizadoras e ferroviárias, bem como a consequente "vinda" - na verdade, contratação - de profissionais da cidade lá radicados para a elaboração de projetos e prestação de serviços na regiáo. Tais narrativas caminham paralelamente àquelas que dividem o território do estado em Paraná Tradicional, Sudoeste e Norte (SUZUKI, 2011), baseadas na incapacidade de expansão do primeiro, devido à precariedade de sua economia extrativista e à ausência de vias de comunicação. A dualidade centro-periferia nelas presente é explicitada por Padis (2006, p. 125, grifo nosso): “assim [...] [se] pode perfeitamente concluir que, até o fim da terceira década deste século, o Paraná não passava de uma economia periférica no sistema econômico brasileiro, especialmente no de São Paulo".
9 Abordando a relação centro-periferia desde a intensificação do processo de descentramento e mirando a discussão sobre o regionalismo crítico, Waisman (1993, cap. 4) substitui a definição de periferia pela de região. Sua posição de divergência - propositiva no âmbito da práxis, "desde as margens, tudo é - ou deveria ser - projeto" - revela-se mais crua ainda, do ponto de vista das dinâmicas de circulação de ideias, ao preconizar o abandono ou saída do sistema (WAISMAN, 1993, p. 72-73). 
Figura 1: Área de concessão da CTNP/CMNP no norte do Paraná, com núcleos urbanos

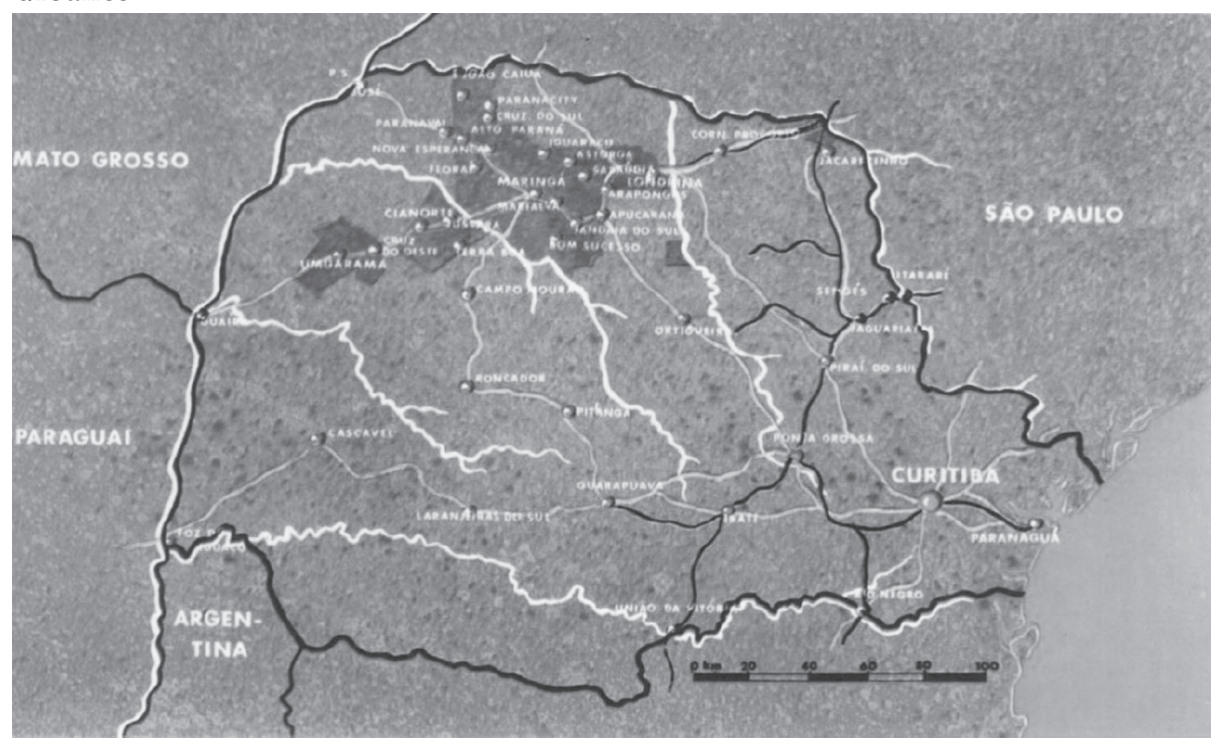

Fonte: Companhia Melhoramentos Norte do Paraná (1975).

Entretanto, para além dos movimentos expansionistas paulistas, alguns fatores estruturais e conjunturais revelam-se decisivos para a ocupação da área de concessão da CTNP/CMNP a partir de fins da década de 1920, como os efeitos da quebra da bolsa de Nova Iorque em 1929, a Revoluçáo de 1930, o Estado Novo em 1937 e a deflagração da Segunda Guerra Mundial (1939-1945).

É preciso lembrar que a compra dos 515.017 hectares de terras no norte do Paraná pela Companhia de Terras Norte do Paraná (CTNP), subsidiária da empresa britânica Paraná Plantations, em 1928, seguiu os moldes da Lei no 2125/1922. Essa lei flexibilizou as condiçôes estabelecidas pela Lei no 1642/1916, passando a liberar concessōes maiores que o limite de 50 mil hectares até então vigente e a possibilitar a venda direta. Medidas drásticas com relação à concessão de terras foram tomadas após a Revolução de 1930, fazendo com que a concessão da CTNP fosse regulada por um marco legal mais permissivo, náo mais existente quando de sua alienaçáo a um grupo de investidores paulistas, em 1944. Esse fato tornou a compra da empresa um negócio atraente. Além disso, a encampação das estradas de ferro pelo governo federal, o controle de remessa de lucros ao exterior e o aumento dos impostos sobre os ganhos estrangeiros, após a implantação do Estado Novo (MONBEIG, 1984, p. 239-240), concorreram para a transaçáo. A isso, deve ser acrescido, igualmente, a promoção do retorno compulsório dos capitais britânicos investidos no exterior por ocasião dos esforços bélicos da Segunda Guerra Mundial (BELOTO, 2004). A razão social da empresa foi alterada de Companhia de Terras Norte do Paraná para Companhia Melhoramentos Norte do Paraná (CMNP), em 1951.

Apesar das iniciativas de incentivo à industrialização, o Estado manteve instrumentos de proteção ao café até então vigentes. Assim, a grande expansão cafeeira antes referida foi fruto, na verdade, de medidas de restrição, mais exatamente, da proibição do plantio de café em 1932, com exceção do Paraná e de outros estados com menos de 50 milhōes de cafeeiros (MONBEIG, 1984; ROSANELI, 2009). Como se observa, não se tratou, portanto, de "negligência" ou de "alienação das possibilidades 
de industrialização" paranaense (PADIS, 2006), mas de desdobramentos de uma dinâmica econômica nacional e mesmo internacional, centrada em transaçóes diretas, na aquisição de matérias primas e alimentos, no consumo de produtos industrializados e no prolongamento do sistema financeiro paulista (FRESCA, 2004). Uma dinâmica econômica que não deve ser vista em termos de uma dualidade centro-periferia a ser superada, mas da manutençáo de um modelo de inserção econômica que reproduz relaçôes de assimetria. Nesse sentido, mais que a expansão do café como um elemento transformador da economia paranaense, ocorreu a materialização de um empreendimento colonizador, ferroviário e urbanizador, inserido em um panorama mais complexo, em que se imbricaram fatores conjunturais nacionais e internacionais, processos de acumulação e de formação do grande capital industrial e financeiro paulista, papéis dos agentes políticos e econômicos paranaenses, entre outros.

\section{VIAS DE TRANSPORTE}

O binômio café-ferrovia é recorrentemente apontado como caracterizador da dinâmica econômica e da configuração do território da área de colonização da CTNP/ CMNP, conferindo-lhe contornos peculiares de modernidade. No entanto, Monbeig (1945) se refere à atuaçáo de ferrovias e estradas como "agentes de povoamento", afirmando que, no intervalo ritmado entre assentamentos, os colonizadores "não utilizaram senão o que uma experiência secular ensinou aos paulistas" (MONBEIG, 1945, p.17).

Por outro lado, a complexidade de tal dinâmica encontra rebatimento na constituição dessa rede de transportes. Segundo Monbeig (1945), a colonizadora britânica projetava um ramal da Sorocabana de Presidente Prudente até a cidade de Londrina; já Rego (2009) sublinha que a empresa havia tentado comprar a Estrada de Ferro Sorocabana, a fim de fazer a conexão ferroviária das suas terras pelo Norte (REGO, 2009). Entretanto, a solução encontrada foi a compra da Companhia Ferroviária São Paulo-Paraná, que já havia transposto o rio Paranapanema em direção a fazendas, sítios, vilas e cidades geradoras de demandas (TOMAZI, 1989, p. 106). Apenas depois disso a companhia passou a obedecer à lógica segundo a qual a loteadora "não abre oficialmente seus loteamentos aos compradores e não intensifica sua propaganda senão quando há a certeza de que serão atingidos logo depois pelos trilhos" (MONBEIG, 1945). O mesmo ocorreu com o traçado da ferrovia, sobre o qual repetidamente se enfatizou o fato de situar-se nos principais espigóes do sítio. De modo diverso, ela transpôs os rios Paranapanema, das Cinzas e Tibagi, para enfim atingir a área concedida. Apenas a partir desse ponto seguiu os divisores de águas entre as bacias do Tibagi, Pirapó e Ivaí; por fim, necessitou cruzar o rio Ivaí para alcançar as terras concedidas da sua margem esquerda. Tomazi (1997) afirma, ainda, que os negócios da CTNP se inseriam na política britânica para a América do Sul, vislumbrando a extensão da ferrovia até o Paraguai, o que aponta não para a adaptação de uma estratégia territorial e comercial "secular", mas sim para uma configuração ligada a uma dinâmica econômica mais ampla. 
Figura 2: Localização das terras da CTNP e ferrovias

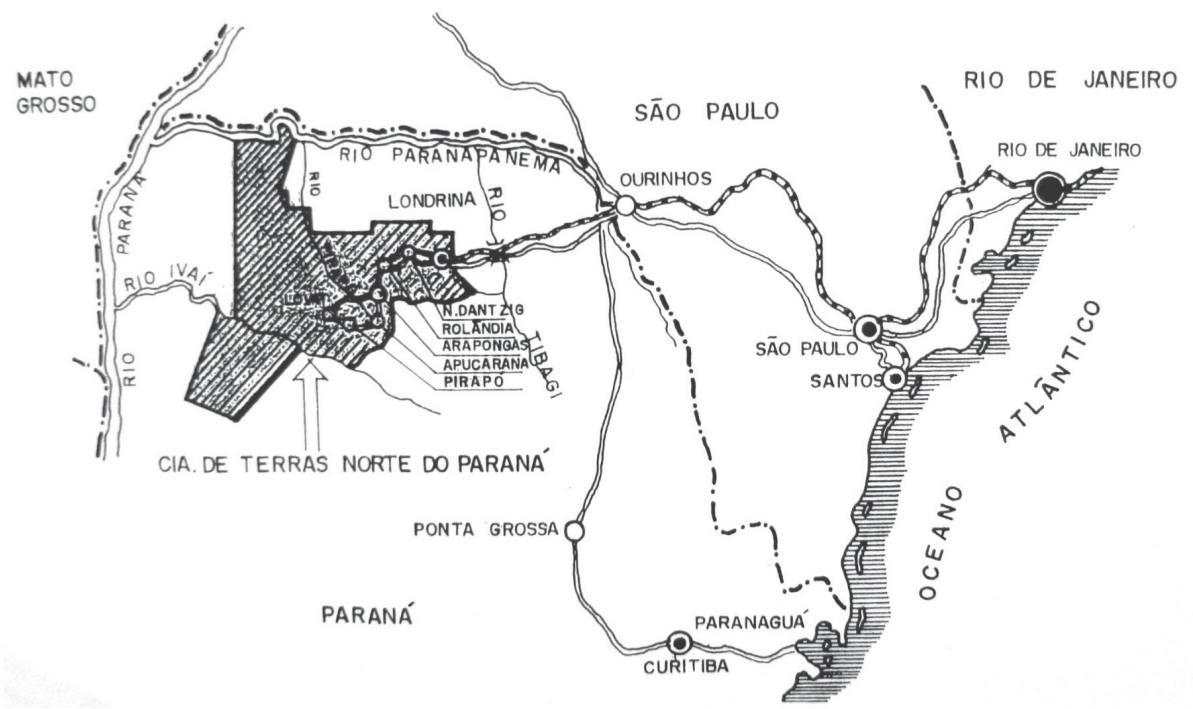

Fonte: Tomazi (1989).

Finalmente, houve a passagem de uma matriz ferroviária para outra, predominantemente, rodoviária. Nessa passagem, ocorreu a mudança de uma estrutura de transportes linear para uma configuração em rede, tendo cidades implantadas em seus cruzamentos (MONBEIG, 1984; CORDOVIL, 2010). Essas transformaçôes correspondem a tendências mais amplas do segundo pós-guerra, do mesmo modo que a estatização das estradas de ferro e a consolidação da indústria automobilística durante a gestão de Juscelino Kubitschek (1956-1961).

\section{ESTRUTURA FUNDIÁRIA}

O debate estabelecido em torno das referências, dos conteúdos e dos sentidos do traçado da ferrovia - exemplo de uma abordagem moderna ou de experiência secular - se prolonga, com maior intensidade, quando a análise se debruça sobre sua expressão espacial, sobre o plano de ocupação e o projeto dos núcleos urbanos. Para além da suposta influência howardiana e da presença do conceito de cidade-jardim no traçado de Maringá, desponta, em diversos trabalhos dedicados aos "modelos urbanísticos” e às referências do urbanismo praticado em São Paulo e implantado no norte do Paraná, a possível afinidade com o town and country planning inglês e com sua crítica. Andrade (2000, p. 9) destaca a presença dessa concepção, bem como as de Soria Y Mata e Miliutin na configuração territorial da rede de cidades da CTNP, dada sua disposição linear em função da ferrovia. Rego (2009) levanta a hipótese de que a companhia teria reconhecido as afinidades de seu plano com o dos britânicos. Segundo o autor, ela intensificou os vínculos com o town and country planning ao inserir "uma espécie de nova projeção dos corolários recentes da garden city sobre o 'esquema' já plantado pelos britânicos no Paraná” (REGO, 2009, p. 182). Outros trabalhos apontam para a ausência, nas "concepçóes locais", de dados sociais e urbanísticos presentes na proposta "original”. Rosaneli (2009) localiza a fragilidade do recorte dessa abordagem, que obnubila a complexidade histórica da fronteira do café, inclusive a "vastíssima experiência" que ultrapassa "os limites setentrionais do esta- 
do". Conforme Monbeig (1945, p. 17), "não há que admirar na colonização do norte do Paraná uma concepção nova dos colonizadores”. Informada do teor do debate sobre o lugar das ideias e da discussão da historiografia urbanística contemporânea, Szmrecsányi (2000, p. 259) resume essa questão com precisão:

\begin{abstract}
A presença local de traços das cidades-jardins constitui, quando muito, uma ideia fora do lugar (Schwarz). Ao sair de seu contexto ela se inverte. A proposta de Howard é esvaziar a metrópole e dar melhores condiçóes de vida aos trabalhadores; a essência do desenho urbano de Unwin, Parker ou Soissons é respeito e integração à natureza, combinados ao resguardo da privacidade e promoção de espaços comunitários. Aqui se modificaram os termos da proposta: o desenho serve para propaganda, para demonstração, para chamariz; a natureza deve ser destruída e disciplinada; não há metrópole a ser esvaziada, mas o vazio a ser preenchido; não são os pobres que se mobilizam, eles são mobilizados pelo capital; a ascensão não é coletiva, é individual; o planejamento regional não brota das necessidades criadas pelo adensamento liberal, mas o adensamento é o objetivo do plano para a regiáo. O alvo não é o homem, é a renovaçáo do capital pelo lucro.
\end{abstract}

No plano das ideias, pelo menos um aspecto informa decisivamente tal proposta: a presença marcante tanto da planificação ou planejamento quanto da questão agrária no vocabulário político-econômico nacional e internacional (GONÇALVES, 1999). O primeiro caso, isto é, da planificação, abrange um campo que vai da publicidade até o planejamento financeiro e físico da companhia colonizadora; já no segundo caso, nota-se um bloqueio do debate em torno da reforma agrária, quando a companhia qualifica o produto de sua atuação como exemplo de "verdadeira, justa e pacífica reforma agrária” (CMNP, 1975, p. 133).

\title{
NÚCLEO URBANO
}

Até o fim do comando britânico da CTNP, o traçado das cidades era marcado pela regularidade da grelha ortogonal, segundo combinaçóes - inflexóes - que incorporavam as características topográficas do sítio (REGO; MENEGUETTI, 2008, p. 39). É curioso observar que somente sob a direção dos paulistas que um "modelo inglês" tenha sido implantado na região, em Maringá e Cianorte, antes da retomada do padrão anterior, em Jussara (1955) e outras cidades. O plano urbanístico de Maringá foi elaborado por Jorge de Macedo Vieira, que estagiou na City of San Paulo Improvements and Freehold Land Company Limited, quando lá atuava Barry Parker. Para Andrade (2000, p. 8), é "inegável que as claras filiações dos traçados urbanísticos do Eng. Jorge Macedo Vieira às soluçóes tipo 'garden city' revelam influências diretas de Parker”. Bonfato (2003, p. 85) discute a aplicação de modelos urbanísticos consagrados internacionalmente no Brasil na primeira metade do século XX, afirmando que Maringá "reflete, além da influência garden city, o modelo city beautiful na adoção do civic center [...] [e] dos carrefours arquetípicas de Hénard e do [sic] beaux arts francês". Mais que buscar ressonâncias de modelos urbanísticos, Andrade e Cordovil (2008, p. 51) focam a construção do território por meio da constituição de uma rede urbana de extração moderna, no bojo da formaçáo de uma cultura urbanística moderna e da construção de cidades novas no Brasil. Cordovil (2011, p. 18) aborda as aproximaçôes e os distanciamentos entre o plano e as referências urbanísticas supracitadas, 
buscando "marcar e desvendar o hibridismo das concepçôes teóricas que embasaram a proposta de Vieira".

As ideias por trás do traçado de Vieira são objeto de interpretaçôes e apropriaçóes desde muito cedo. A própria colonizadora referia-se às chácaras ao redor dos patrimônios como "obedecendo a um critério urbanístico dos mais modernos, que inclu[ía], ao redor da zona urbana, um 'cinturáo verde'” (CMNP, 1975, p. 146). Já o primeiro plano diretor definia a cidade como um "expoente e exemplo nacional de um padrão que se convencionou a chamar de 'cidade jardim”” (MARINGÁ, 1967, p. 23), baseado nos "princípios de zoneamento enunciados na Carta de Atenas", "segundo um critério que nos parece, entretanto, mais ajustado a uma política de promoção de vendas" (MARINGÁ, 1967, p. 190). Por um lado, a malha urbana possuía um traçado regular, ora radioconcêntrico, no caso de algumas de suas áreas residenciais, ora ortogonal, no centro da cidade, ora mais simétrico, como o da via que ligava a praça à estaçáo ferroviária e ao centro cívico da cidade, mesclando, fluidamente, soluçôes formais e referências conceituais. Por outro, como bem assinalou Peter Hall (2002), o modelo proposto por Howard no final do século anterior tinha uma conotação mais social do que física; semelhantemente, Lewis Munford, na introdução a uma das ediçóes de Garden Cities of Tomorrow (1946), afirmou que Howard estava menos interessado em formas físicas que em processos sociais. O certo é que, como mostra Hall (2002, p. 120), tanto na Europa quanto na América, "a tradição cidadejardim jamais conheceu uma urbanização nos moldes preconizados por Howard”.

Figura 3: Anteprojeto da Cidade de Maringá. Jorge de Macedo de Vieira, meados da década de 1940

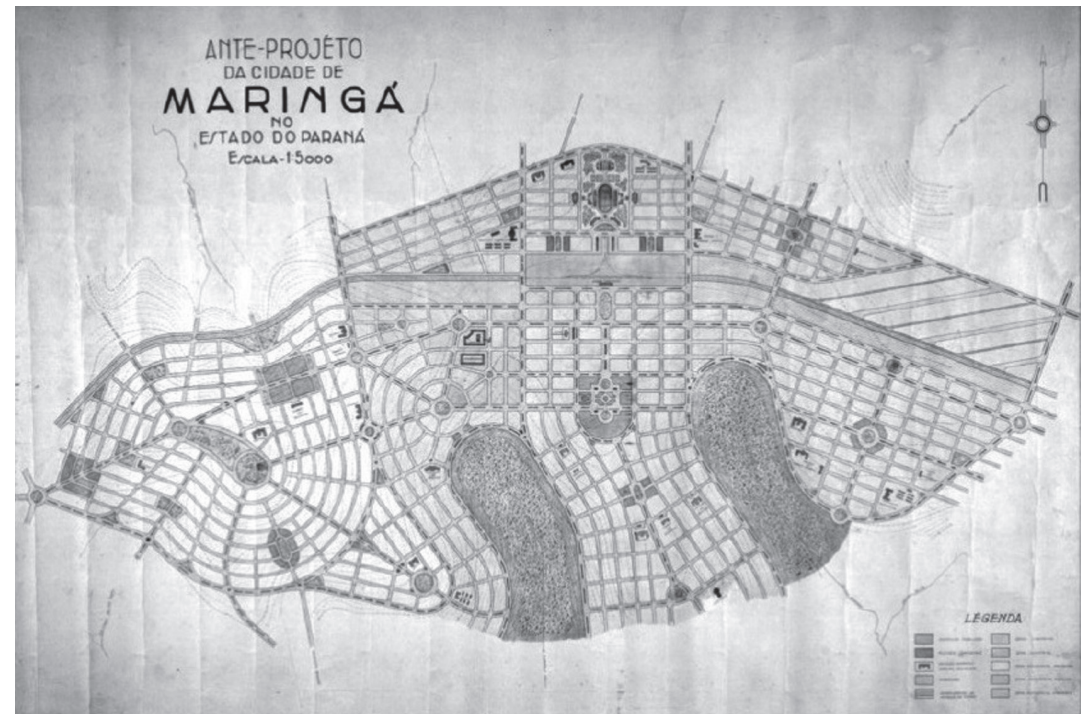

Fonte: Acervo do Departamento do Patrimônio Histórico - São Paulo.

Considerando esses pontos, uma indagação pode ser feita: seria a intenção da companhia buscar aquilo que de mais avançado circulava na metrópole como solução para uma sociedade em transformação ou sua atuação se tratava de uma estratégia comercial, visando à promoção do empreendimento? Ainda que com um traçado mais refinado que o da costumeira grelha ortogonal, o plano urbanístico reproduz, em essência, a mesma cidade feita de quadras, com lotes direcionados à venda. Baseados 
nos elementos documentais pesquisados, a motivação da contratação do profissional pela CMNP e o arcabouço teórico que embasou o plano ainda permanecem em aberto. Tais elementos sugerem cautela em relação à interpretação do norte do Paraná como palco de inovação ou de singularidade. Monbeig (1945, p. 17) salienta que o que seria realizado aqui poderia ser considerado como "muito empirismo aplicado em grande escala e aplicado racionalmente"; com isso, ele se referia não apenas aos traçados das cidades, mas também às teorias que os informavam.

\section{UM EPISÓDIO ARQUITETÔNICO: O CENTRO CÍVICO E AS INTENÇÕES MODERNAS}

A literatura sobre a arquitetura das primeiras décadas de Maringá tem privilegiado a produção autoral, revelando especial interesse em inserir profissionais que atuaram na regiāo e, por conseguinte, a própria regiáo na narrativa da arquitetura moderna brasileira. Esse intento a torna usualmente aberta à noçáo de difusão da arquitetura moderna ao interior, através da atuação dos "arquitetos peregrinos, nômades e migrantes" (SEGAWA, 1997, p. 9-13) que partiram dos grandes centros - Rio de Janeiro e São Paulo - para as regiôes mais distantes do país. Outras abordagens debruçam-se sobre a adaptação de soluçôes formais e construtivas da arquitetura moderna brasileira, apontando para um "modernismo de fachada", que, "mesmo não apresentando em sua totalidade os princípios modernos" (DELMONICO, 2010, p. 5), teria como virtude o fato de expressar uma eventual pluralidade cultural da zona de fronteira. Essas e outras leituras enfocam, de modo comum, a questão da identidade nacional e suas derivaçóes locais, aspectos característicos das elaboraçôes geradas no âmbito do projeto modernizador brasileiro.

\section{QUADRO DA ARQUITETURA NA REGIÃO PIONEIRA}

Remontando à infância da cidade de Maringá e abrangendo quase três décadas de sua existência, a atuação de José Augusto Bellucci é tida como representativa de uma cidade que, fruto de um plano urbanístico moderno, buscava, incessantemente, o novo por meio de iniciativas de diferentes lideranças da CMNP, da municipalidade e da Igreja Católica. Não obstante, outras manifestaçôes arquitetônicas demarcam a trajetória da cidade. A presença de arquitetos ilustres na cidade é objeto de atenção recorrente por parte da historiografia local, que, ao promovê-los, promove simultaneamente a cidade e sua arquitetura no cenário nacional.

Em 1956, Maringá recebeu dois arquitetos de "renome", Rino Levi e Roberto Cerqueira César, a convite da Associação de Engenheiros local. Essa visita decorria de um projeto da agência local do Banco Sul Americano do Brasil, que fazia parte do grupo de empresas pertencentes aos acionistas da Companhia Melhoramentos Norte do Paraná e para o qual o escritório já trabalhava (CORDOVIL, 2010; REGO, 2012). A primeira versão do projeto, de 1955, previa um volume único de três pavimentos com pilares metálicos; no térreo, ficaria a agência bancária e, nos pavimentos superiores, os apartamentos. A solução definitiva acabou apresentando dois volumes de dois pavimentos, em estrutura de concreto e alvenaria: um volume para a agência bancária, outro para os apartamentos. 
Por sua vez, Salvador Candia projetou, em 1962, um edifício para o Banco de Lavouras de Minas Gerais. O projeto reproduzia um arranjo misto de agência bancária e torre de apartamentos que havia realizado em Sáo Paulo e em outras cidades brasileiras entre as décadas de 1950 e 1960. Quando observados, além de não se tratar da "importação" de uma grife, tais edifícios revelam vetores normalmente desprezados de circulação da arquitetura moderna no território, notadamente aqueles concernentes às atividades bancárias, da indústria da construção civil e do mercado imobiliário de São Paulo e de outras regiôes do país, bem como materializam uma ideia de modernidade ligada à verticalização e ao morar moderno.

Figura 4: Perspectiva do Banco Lavouras de Minas Gerais em Maringá. Projeto de Salvador Candia

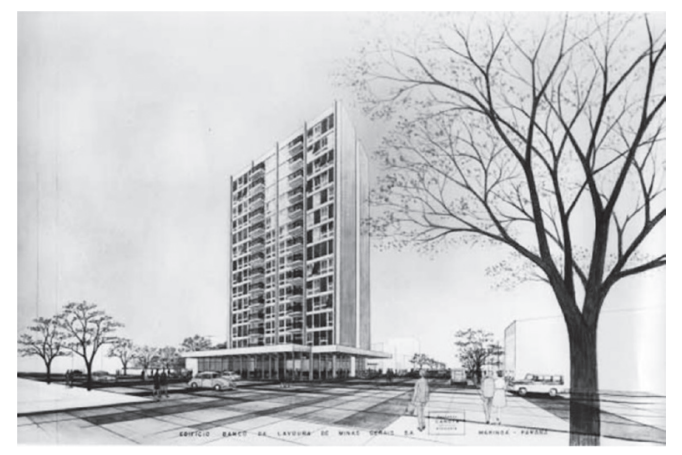

Fonte: Acervo S. Candia, consultado em Ferroni (2008).

\section{GRANDE HOTEL}

O próprio José Augusto Bellucci foi contratado para conceber o Grande Hotel Maringá, (1951) após projetar, por indicação de Cássio da Costa Vidigal, então diretor-presidente da CMNP, a casa de um dos diretores dessa companhia em São Paulo (VERRI JÚNIOR, 2001). O programa hoteleiro era típico de cidades novas, pois era preciso "hospedar bem para atrair bons compradores de terras" (CMNP, 1975, p. 124). Sua realização condensou questôes que marcaram os primeiros anos de produção do espaço maringaense, em especial a relação entre a companhia e a municipalidade recémcriada. O hotel se localizaria na área destinada, pelo plano de Vieira, à igreja matriz e a outros edifícios de uso público. Ele se beneficiou de uma lei que isentava de impostos municipais os hotéis que estivessem em construção na cidade no prazo de cinco anos de sua publicaçáo, desde que atendessem aos parâmetros nela descritos.

O prédio foi executado pela Construtora de Imóveis São Paulo, de propriedade de Cassio da Costa Vidigal. Em sua inauguração, foram hasteadas as bandeiras do Paraná, do Brasil e de São Paulo. O primeiro anteprojeto era marcado pela verticalidade e por amplas superfícies envidraçadas; sua arrojada concepção previa, inclusive, a ampliação em altura, "deixando-se pronta, sempre, a estrutura do andar imediatamente superior” (VERRI JÚNIOR, 2001). Ele foi recusado, entre outros motivos, por ser "impróprio para o momento e o local, a construção d[e] [um] edifício com vários andares e de linhas acentuadamente modernas".

Após uma série de estudos marcados pela simetria e disposição pavilhonar, chegou-se ao segundo e definitivo anteprojeto: o edifício seria estruturado em blocos or- 
togonalmente dispostos entre si formando pátios, ainda que isso "[...] acarretasse [seu] alastramento [...]". Da mesma forma que o projeto de Levi para a agência do Banco Sul Americano do Brasil, o arrojado desenho inicial foi substituído por concreto armado e alvenaria revestida com argamassa ou litocerâmica, esquadrias de madeira, cobertura de telhas de fibrocimento com beirais revestidos de madeira e com ventilação do forro, além de ventilação cruzada nos apartamentos através de venezianas sobre as portas.

Nesse sentido, embora arquitetos como Bellucci e Levi promovessem a circulação de ideias mais avançadas, elas eram refutadas pelos contratantes. Diante disso, eles acabavam recorrendo a soluções baseadas na conciliação de modernidade e tradição - no caso "materiais e mão de obra locais", algo teorizado e aplicado por Lucio Costa no pré-guerra, mas que ele mesmo considerou superado quando da realizaçáo de Brasília (1960). A modernidade do Grande Hotel decorre, assim, não só de seus aspectos arquitetônicos, mas também de sua inserção no quadro da modernização local.

Figuras 5 e 6: Primeira perspectiva do Grande Hotel Maringá e edifício construído, evidenciando as modificaçôes, 1957
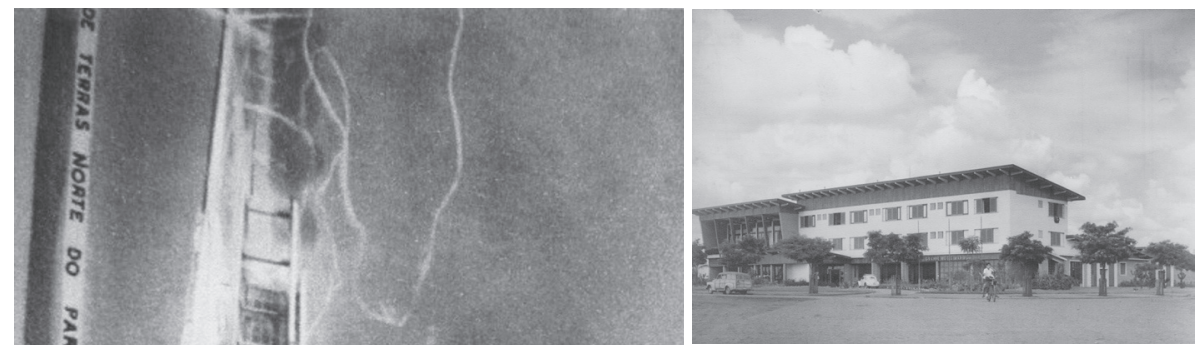

Fonte: Acervo Bellucci, consultado em Verri Júnior (2001).

Fonte: Acervo do Museu da Bacia do Paraná.

\section{Catedral}

Ao ter o sítio previsto por Vieira para sua implantação ocupado pelo hotel, a igreja matriz foi construída, em 1950, no aro destinado, inicialmente, à edificação de prédios públicos. Com a criação do bispado em 1957, a construção da catedral se deu efetivamente no centro desse semicírculo, no vértice do eixo formado pela praça $\mathrm{D}$. Pedro II, Avenida Getúlio Vargas e praça da estação - área que fora deixada vazia na proposta de Vieira. As relaçóes espaciais inicialmente previstas foram, assim, invertidas, com as construçóes em volta dela sendo demolidas, entre as quais o Centro de Saúde construído em 1956, a fim de criar a praça que atualmente a emoldura.

Essas mudanças são significativas, já que expressam valores que regem a concepção urbanística do engenheiro, bem como sua recepção tanto pelo contratante quanto pelo meio social local. Uma das hipóteses é que o primeiro bispo, Dom Jaime Luis Coelho, teve influência nessa decisão. O Código de Posturas e Obras (Lei 34/1959) fazia referência ao sítio em que se implantou a catedral e seu entorno, sendo que seu artigo $3^{\circ}$ foi assim redigido: "destina-se à construção de edifícios públicos - é o Centro Cívico - Arquitetura moderna”. Esse era o interesse de vários agentes. Conforme Robles (2007, p. 161):

No decorrer dos anos 50, com frequência os diretores da CMNP faziam-se presentes em Maringá. Convivência respeitosa marcou o relacionamento entre o bispo e, em particular, 
o diretor-gerente Hermann Moraes de Barros. Foi dele a iniciativa de apresentar-lhe o arquiteto José Augusto Bellucci, com escritório instalado na Praça da República, em São Paulo, onde esteve Dom Jaime para expor sua foto de jornal enriquecida dos elementos que a transformavam em catedral.

Ao contrário das narrativas correntes, a "foto enriquecida de elementos" a que se refere Robles não é a do Sputnik, com a qual os soviéticos tomaram a liderança na corrida espacial, mas, sim, da ogiva por meio da qual a Martin Company pretendia pôr em órbita o primeiro satélite norte-americano. Sobre a ogiva, o bispo, como se narra, teria desenhado uma cruz: "até no detalhe do último lance do cone, no espaço reservado ao mirante e aos carrilhóes, aquele recorte de jornal revelava a estrutura básica da futura catedral [...]" (ROBLES, 2007, p. 161). Circulam outras versóes para o episódio, como a de José Carlos Bellucci, filho do arquiteto, que, em 2005, afirmou que a concepção arquitetônica partiu de uma imagem de mãos postas em oração.

Figura 7: Foto da construção da catedral em contraste com a antiga igreja de madeira, 1970

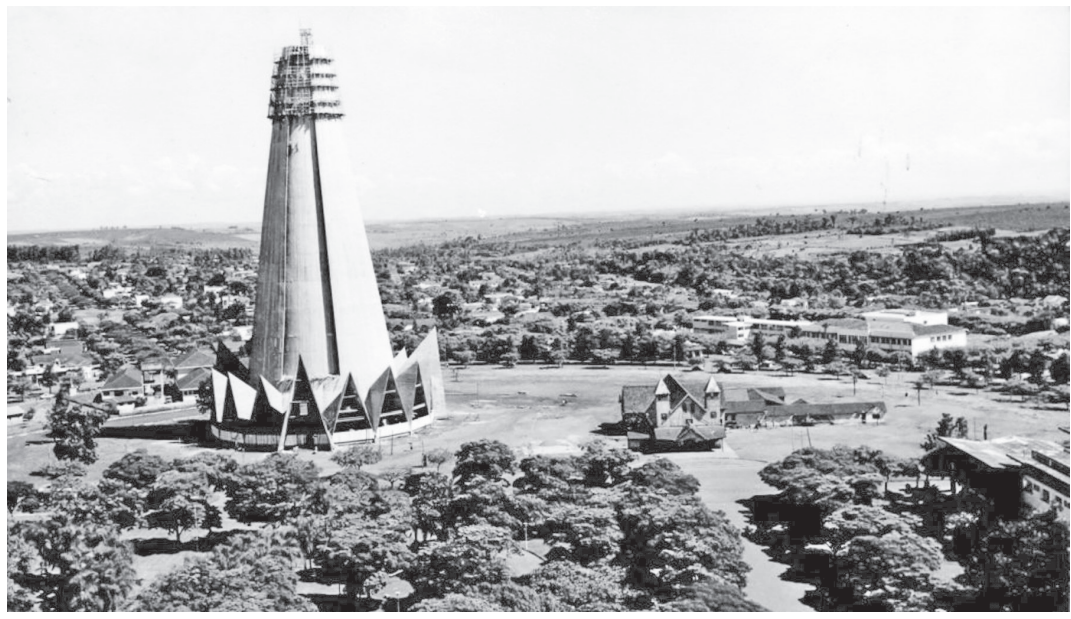

Fonte: Acervo do Museu da Bacia do Paraná.

Na realização da catedral, destaca-se a atuação de uma série de agentes, como a municipalidade, os bancos, as associaçôes, os empresários e até mesmo as açôes públicas, por exemplo, as campanhas do café. Em vez de limitar a análise a interpretaçôes segundo as quais o projeto inovava ao apresentar "precocemente na região a estética em voga na 'escola paulista"' (REGO, 2012, p. 8), a catedral pode ser considerada parte integrante da própria construção social da cidade de Maringá, cuja trajetória engloba, entre outros fatores, a interlocuçáo com a arquitetura moderna através dos traços do arquiteto paulistano.

\section{PAÇO MUNICIPAL}

O projeto do Paço Municipal (1967) foi elaborado pelo escritório de Bellucci quando vigorava a Lei 418/1965, que estabelecia critérios para a sua construção, assim como da Câmara Municipal e da Biblioteca Municipal. O artigo $1^{\circ}$ dessa lei definia que os edifícios tinham de ser concebidos "dentro da técnica moderna", devendo ser a área não 
edificada ajardinada e arborizada de acordo com a "técnica moderna de urbanização".

A exemplo do primeiro anteprojeto do Grande Hotel, destacava-se o volume verticalizado, fechado por extenso pano de vidro e estruturado em concreto protendido, com vão de 40 metros, que, segundo Verri Júnior (2001), foi calculado utilizando-se um computador da Escola Politécnica da Universidade de São Paulo (EPUSP). Curiosamente, esse bloco acabou não sendo executado, apesar de a proposta de verticalizaçáo, já presente no Grande Hotel, como visto, ser condizente com a monumentalidade e a importância ambicionada por um edifício projetado para ser a sede municipal.

Novamente, embora os profissionais de arquitetura e engenharia concebessem os edifícios utilizando parâmetros técnicos e construtivos "modernos" requeridos pela sociedade e pela lei, seus projetos eram reprovados ou modificados, de maneira que a "técnica moderna" incentivada pela municipalidade, na realidade, não se concretizava em sua totalidade, revelando as possibilidades e limites da complexa teia de agentes, condicionantes e intençôes modernizadoras entấo vigentes.

\section{CONCLUSÃO}

A retomada do debate lançado por Schwarz (2000) e Carvalho Franco (1976) e alguns de seus desdobramentos recentes propicia uma entrada privilegiada no universo das dinâmicas de circulação de ideias, permitindo compreender a complexidade das questóes nelas em jogo.

Nessa perspectiva, a atençáo a aspectos da conjuntura histórica e econômica revela-se importante para a compreensão de conteúdos modernizadores do processo de colonização e urbanização do norte do Paraná. Como demonstrado, os grandes eventos em escala mundial e nacional, a trajetória das políticas da cafeicultura ao longo do tempo, as relaçóes estabelecidas com o capital industrial e financeiro de São Paulo são elementos relevantes para o entendimento e descrição de tal processo. A apresentação do avanço das vias de comunicação a partir de Curitiba e de São Paulo, tanto na área colonizada quanto fora dela, acompanhando divisores de águas ou cruzando rios caudalosos, é igualmente significativa. Esses últimos aspectos revelam, por sua vez, o papel das elites políticas e econômicas paranaenses e paulistas, bem como o impacto da sucessão de transformaçóes tecnológicas ocorridas ao longo da Segunda Revolução Industrial sobre a ocupação e urbanização do território e sobre a configuração do empreendimento colonizador. Tais questôes são especialmente nítidas na eleição de referências urbanísticas pela companhia colonizadora, pela prefeitura e pela historiografia, especialmente nas análises elaboradas a posteriori sobre o plano urbanístico de Maringá. Concernente a tais análises, as consideraçôes sobre a relação entre forma artística e conteúdo social, a "visão esteroscópica" benjaminiana, revelam-se fundamentais. Seus horizontes promissores são aqui apenas vislumbrados, tanto no que se refere ao plano urbanístico quanto na arquitetura da cidade e sua materialização.

Pelo exposto, o artigo pode contribuir para a discussão de abordagens voltadas à elucidação de dinâmicas por trás da produção social da paisagem urbana brasileira, especificamente dos espaços edificados de Maringá e do norte do Paraná. Nele, enfatizou-se a ligação estabelecida entre os projetos modernizadores, os ideais de modernidade e seus espaços e o ambiente social em que estes se inserem e do qual sáo resultados.
Ana Carolina Pussi de Brito é graduada e mestre em Arquitetura e Urbanismo pela Universidade Estadual de Maringá (UEM); arquiteta no Ministério da Educação (MEC).

E-mail: acpdebrito@gmail. com.

André Augusto de Almeida Alves é graduado, mestre e doutor em Arquitetura e Urbanismo pela Universidade de São Paulo (USP); professor adjunto no Departamento de Arquitetura e Urbanismo da Universidade Estadual de Maringá (DAU/UEM).

E-mail:aaaalves@uem.br.

Artigo recebido em 9 de julho de 2015 e aprovado para publicação em 29 de dezembro de 2015. 


\section{REFERÊNCIAS}

ALAMBERT, F. Lugar da Dialética, Dialética do Lugar. In: MUSSE, R.; LOUREIRO, I. (Org.). O marxismo Ocidental. São Paulo: Ed. UNESP, 1998. v. 1, p. 229-247.

ALMANDOZ, A. Planning Latin America's capital cities 1850-1950. Londres: Routledge, 2002.

ANDRADE, C. R. M. Ressonâncias do tipo cidade-jardim no urbanismo de cidades novas no Brasil. In: SEMINÁRIO DE HISTÓRIA DA CIDADE E DO URBANISMO, 6., 2000, Natal. Anais do VI Seminário de História da Cidade e do Urbanismo. Natal: PPGAU/UFRN, 2000.

; CORDOVIL, F. C. S. O projeto moderno e a transformação da paisagem: a cidade de Maringá no noroeste paranaense. In: SEMINARIO APEC. La producción del conocimiento y los desafíos (in) sostenibles del mundo contemporáneo, 13., 2008, Barcelona. Anales del Seminario APEC. Barcelona: APEC, 2008. p. 47-56.

ARANTES, P. E. Sentimento da Dialética da Experiência Intelectual Brasileira. Dialética e Dualidade segundo Antônio Candido e Roberto Schwarz. São Paulo: Paz e Terra, 1992.

BELOTO, G. E. Legislação urbanistica: instrumento de regulação e exclusão territorial considerações sobre a cidade de Maringá. 2004. 201 f. Dissertação (Mestrado em Geografia) - Universidade Estadual de Maringá, Maringá, 2004.

BONFATO, A. C. Jorge de Macedo Vieira: o orgânico e o geométrico na prática urbana (19201960). Revista Brasileira de Estudos Urbanos e Regionais, v. 5, n. 2, p. 75-93, nov. 2003.

CANCLINI, N. G. Culturas híbridas: estratégias para entrar e sair da modernidade. 2. ed. São Paulo: Edusp, 1998.

CARVAlHO FRANCO, M. S. As ideias estão no lugar. Cadernos de Debate, São Paulo, n. 1, p. 61-64, 1976.

COMPANHIA MELHORAMENTOS NORTE DO PARANÁ - CMNP. Colonização e desenvolvimento do Norte do Paraná. São Paulo: CMNP, 1975.

CORDOVIL, F. C. S. A aventura planejada: engenharia e urbanismo na construção de Maringá - 1947 a 1982. 2010. Tese (Doutorado em Arquitetura e Urbanismo) - Escola de Engenharia de São Carlos, Universidade de São Paulo, São Carlos, 2010.

Referências Teóricas e Urbanísticas do Plano Inicial de Maringá: Aproximações e Distanciamentos. In: ENCONTRO NACIONAL DA ANPUR, 14., 2011, Rio de Janeiro. Anais do XIV Encontro Nacional da Anpur. Rio de Janeiro: ANPUR, 2011.

DE ANGELIS, B. L. D. et al. A (des)mistificação do "verde" de Maringá - um desafio a ser (re)pensado. In: MACEDO, O. L. C.; CORDOVIL, F. C. S; REGO, R. L. (Org.). Pensar Maringá: 60 anos do Plano. Maringá: Massoni, 2007. p. 47-67.

DELMONICO, Renato. A Arquitetura modernista nas residências de Maringá: apropriações culturais (1950-1970). 2010. Dissertação (Mestrado em História) - Universidade Estadual de Maringá, Maringá, 2010.

FERRONI, E. R. Aproximaçóes sobre a obra de Salvador Candia. 2008. Dissertação (Mestrado em Arquitetura e Urbanismo) - Faculdade de Arquitetura e Urbanismo, Universidade de São Paulo, São Paulo, 2008.

FRESCA, T. M. A rede urbana do Norte do Paraná. Londrina: Eduel, 2004.

GONÇALVES, J. H. R. Quando a imagem publicitária vira evidência factual: versões e reversóes do Norte do Paraná - 1930-1970. In DIAS, R. B.; GONÇALVES, J. H. R. (Org.). Maringá e o Norte do Paraná: estudos de história regional. Maringá: EDUEM, 1999. p. 88-121.

HALL, P. Cidades do amanhã. Uma história intelectual do planejamento e do projeto urbano no século XX. São Paulo: Perspectiva, 2002.

MANTEGA, G. Teoria da dependência revisitada: um balanço crítico. São Paulo: EAESP/ FGV/NPP, 1997. 
MARINGÁ. Prefeitura Municipal. Plano Diretor de Desenvolvimento. Maringá: Prefeitura Municipal de Maringá, 1967.

MONBEIG, P. A zona pioneira do Norte-Paraná. Boletim Geográfico, São Paulo, ano III, n. 25, p. 11-17, 1945.

. Pioneiros e fazendeiros de São Paulo. São Paulo: Hucitec, 1984.

MULLER, N. L. Contribuição ao estudo do norte do Paraná. Boletim Paulista de Geografia, São Paulo, n. 22, p. 53-98, mar. 1956.

OLIVEIRA, F. A economia brasileira: crítica à razão dualista. São Paulo: Boitempo, 2003.

PADIS, P. C. Formação de uma economia periférica: o caso do Paraná. Curitiba: IPARDES, 2006.

PALTI, E. El problema de las “ideas fuera de lugar" revisitado. Más allá de la historia de "ideas”. Mexico, DF: UNAM CCyDEL, 2002.

REGO, R. L. As cidades plantadas: os britânicos e a construção da paisagem do norte do Paraná. Londrina: Humanidades, 2009.

Importing planning ideas, mirroring progress: the hinterland and the metropolis in mid-twentieth-century Brazil. Planning Perspectives, v. 27, n. 4, p. 625- 634, 2012.

; MENEGUETTI, K. S. O território e a paisagem: a formação da rede de cidades do norte do Paraná e a construção da forma urbana. Paisagem e Ambiente, São Paulo, v. 25, p. 37-54, 2008.

ROBLES, Pe. O. A igreja que brotou da mata. Os cinquenta anos da Diocese de Maringá. Maringá: Dentalpress, 2007.

ROCHA-PEIXOTO, G. Marina Waisman: o interior da história. Resenhas Online Vitruvius, São Paulo, ano 13, n. 145.02, jan. 2014. Disponível em: <http:/www.vitruvius.com.br/ revistas/read/resenhasonline/13.145/5035>. Acesso em: $15 \mathrm{dez} .2015$.

ROSANELI, A. F. Cidades novas da fronteira do café: história e morfologia urbana das cidades fundadas por companhias imobiliárias no norte do Paraná. 2009. 268 f. Tese (Doutorado em Arquitetura e Urbanismo) - Faculdade de Arquitetura e Urbanismo, Universidade de São Paulo, São Paulo, 2009.

SCHWARZ, R. Nacional por substração. In: Que horas são? São Paulo: Companhia das Letras, 1987. p. 29-48.

As Ideias fora do lugar. In: Ao vencedor as batatas: forma literária e processo social nos inícios dos romances brasileiros. São Paulo: Duas Cidades; Ed.34, 2000. p. 11.

SCHWARCZ. L.; BOTELHO, A. Ao vencedor as batatas 30 anos: crítica da cultura e processo social, entrevista com Roberto Schwarz. RBCS, v. 23, n. 67, p. 147-160, jun. 2008.

SEGAWA, H. Arquiteturas no Brasil. 1900-1990. São Paulo: EDUSP, 1997.

SUZUKI, J. Idealizaçóes de Modernidade: Arquitetura dos Edifícios Verticais em Londrina 1949-1968. Londrina: Kan, 2011.

SZMRECSANYI, M. I. O modelo das cidades-jardins no norte do novo Paraná. PÓS-Revista do Programa de Pós-Graduação em Arquitetura e Urbanismo da FAUUSP, São Paulo, v.1, n.8, p. 178-197, dez. 2000.

TOMAZI, N. Certeza de lucro e direito de propriedade: o mito da Companhia de Terras Norte do Paraná. 1989. 254 f. Dissertação (Mestrado em História) - Universidade Estadual Paulista Julio de Mesquita Filho, Assis, 1989.

Norte do Paraná: histórias e fantasmagorias. 1997. Tese (Doutorado em História) Universidade Federal do Paraná, Curitiba, 1997.

WAISMAN, Marina. El interior de La Historia: Historiografia arquitectónica para uso de Latino americanos. 2. Ed. Bogotá: Escala, 1993.

VERRI JÚNIOR, A. A obra de José Augusto Bellucci em Maringá. 2001. 148 f. Dissertação (Mestrado em Arquitetura e Urbanismo) - Faculdade de Arquitetura e Urbanismo, Universidade de São Paulo, São Paulo, 2001. 